\title{
Positional equity and equal sacrifice: design principles for an EU-wide income tax?
}

\author{
Peter J. Lambert* \\ University of Oregon, USA
}

\begin{abstract}
Conditions are explored under which a putative EU-wide layer of income tax, additional to the national income taxes of the Member States, would: (a) be horizontally equitable, taking the equals in different EU counties to be those at the same percentile points in the country-specific income distributions, assuming these to differ in logarithms by location and scale only; (b) satisfy an extended equity criterion, that of equal progression among equals; and (c) engender equal sacrifices from the citizens of each country in terms of rank-dependent and utilitarian social evaluation functions. Numerical simulations are undertaken to explore the form that such an EU-wide income tax would take and the properties it would have.
\end{abstract}

\section{Introduction}

The prospect - or, in the UK at least, the spectre - of an EU income tax occasionally looms, both in the popular press and also in the European Parliament. To whit, consider the old headline "Now Britain faces single European tax system: France and Germany spearhead plan to control revenue and social security" in The Independent newspaper of $16^{\text {th }}$ January 1997, and the article, nine years on, entitled "Now EU wants a $£ 510$ income tax" in The Daily Express newspaper of December $31^{\text {st }} 2006$, which was prompted, no doubt, by the opinion expressed at a recent EU summit by M. Jose Maria Gil-Robles, President of the European Parliament, that "the direct taxation of the people would more closely involve individual citizens with the European government". A certain UK web blogger noted, in reaction to this news, "Oh Brilliant. We already shell out billions of pounds for an organisation we don't want to be in as well as having to put up with stupid laws that they shove on us ... When will it end? If they do manage to get a European income tax I will refuse to pay it. Even if it means jail time". It is worth noting, however, that economists do not, as yet at any rate, advocate an EU-wide income tax (see e.g. Cnossen 2002 on this).

\footnotetext{
* This paper was drafted whilst I was a Visiting Professor in the Department of Economics at the University of Otago. I am most grateful for the hospitality provided. I also thank Serge Kolm, Panos Tsakloglou, Udo Ebert, Ivica Urban and Mark Chandler for helpful comments.
} 
In this paper, we consider the putative introduction of an EU-wide layer of income tax, additional to the national income taxes of the Member States, whose revenue would go directly to the centre. The tax would be levied on disposable income in each country, i.e. on income net of domestic income tax. One can imagine the new tax being levied at a universal flat rate on all disposable incomes throughout the EU, in order not to interfere with relative income differentials between and within countries. It is a small leap from there to suppose that a concessionary rate for the poorest countries might be instituted, and another small leap to a plethora of flat rates, negotiated country-by-country by the politicians, and perhaps to the introduction of progression.

For systematic analysis, the question of an EU-wide social welfare function (henceforth SWF) arises, in which a person's domicile may or may not be a relevant factor. However, as shown by Cubel and Lambert (2002a, 2002b), if domicile is not relevant to social welfare, and a common income tax were devised, applicable in all countries, then both overall welfare and inequality could potentially be improved by allowing an element of differentiation into this tax - thereby, at least on the face of it, admitting horizontal inequity. ${ }^{1}$

If allowance is made for differences in the taxable capacities of citizens of the different Member States, then of course horizontal inequity does not automatically follow from different within-country tax treatments. Recent research shows that, depending on the mechanism that identifies the equals across countries, an extended equal treatment characteristic, that of equal progression among equals, which could be said to supplement both the vertical and horizontal aspects, may also be achievable - alongside both vertical equity and classical horizontal equity (Ebert and Lambert, 2004).

How should we identify the equals across the EU countries? Ought we to admit of differences in need or social desert based on domicile? As between an income unit in Luxembourg having $€ 20,000$ p.a. net of domestic tax and an income unit in Latvia also having $€ 20,000$ p.a. net of domestic tax, which is socially the more deserving of an additional euro? Arguably the one in Luxembourg suffers more relative deprivation than

\footnotetext{
${ }^{1}$ In the case of proportional taxes, and a group of countries which can be divided into poorer and richer subgroups in a specific sense (see ibid.), relative to taxing everybody at a common flat rate, vertical equity is enhanced by taxing people in the poorer subgroup at a lower flat rate, and in the richer subgroup of countries at a higher flat rate.
} 
the one in Latvia, being further down its country-specific distribution of living standards (Runciman, 1966); but would this merit a more lenient income tax in Luxembourg? Does not one's intuition go the other way? There is an interesting issue here for income tax design.

In what follows, we explore the possibilities for equitable income taxation across EU member countries under the assumption that the equals in the different countries are those at the same percentile points in their within-country net income distributions, and under the additional assumption that the within-country net income distributions differ in logarithms only by location and scale - as would be the case, for example, in a world of lognormal income distributions. ${ }^{2}$ Clearly this "positional" method of identifying the equals, which has echoes of Roemer's (1998) argument that those who supply equivalent effort are at the same percentile position in their respective distributions, ${ }^{3}$ would result in the different tax treatment of an income unit in Luxembourg having €20,000 p.a. net and an income unit in Latvia also having $€ 20,000$ p.a. net. We shall be able to examine the appropriate differences in tax treatment of such income units shortly.

The structure of the paper is as follows. In Section 2, we explain the procedure for identifying the equals in different EU countries and define the appropriate criteria for both classical horizontal equity and an extended equity command, equal progression among equals, in an EU-wide layer of income tax. In Section 3, we introduce the positional equity concept, and identify the criterion for achieving positional equity across the EU under the assumption that the member countries' income distributions differ in logarithms only by location and scale. In Section 4, we divert to briefly discuss equal sacrifice taxation in case the social evaluation function takes a mixed utilitarian and rank dependent form, in which case one's tax liability is a function of both one's income and one's percentile in the income distribution. In Section 5 we explore normative conditions under which the positionally equitable EU income tax could be regarded as engendering equal sacrifices within each EU country. Section 6 considers what such a tax system

\footnotetext{
${ }^{2}$ These assumptions were articulated in Lambert (2004a) and briefly explored there.

${ }^{3}$ See Roemer (2006) for a nice encapsulation: "In measuring an individual's effort, we should attempt to sterilize out that aspect of effort which is attributable to circumstance. A simple way of doing so is to identify an individual's degree of effort with the quantile which he or she occupies on the distribution of advantage of his or her type" (p. 235). In the present context, we can think of positional equity in terms of "sterilizing out" the effects of circumstance qua birthplace/domicile from peoples' fortunes.
} 
would look like in practice, and also contains some final remarks about the EU as a community of redistribution.

\section{A putative EU-wide income tax: equity criteria}

For simplicity, let us confine attention to two countries, A and B say, and let us assume that a person's domicile enters into the SWF as well as his or her net income level. Then, following Ebert's (2000) approach, set in the general context of social heterogeneity in a population, we may introduce an equivalent income function to conduct the business of identifying the equals across countries in terms of their living standards. For country A, we express living standard in terms of net money income. For country B, a function $S$ : $\mathfrak{R}^{+} \rightarrow \mathfrak{R}^{+}$is invoked, to express as $S(x)$ the equivalent living standard in country A of a citizen of country B who has a nominal net income level of $x$. The function $S(x)$ need only be continuous and strictly increasing (Ebert, 2000). For $n>2$ countries, say A and $\mathrm{B}_{1}, \mathrm{~B}_{2} \ldots \mathrm{B}_{\mathrm{n}-1}, n-1$ such functions would be needed.

A citizen of country A with net income $x_{A}$ and a citizen of country B with net income $x_{B}$ will be equals if and only if $S\left(x_{B}\right)=x_{A}$. Let the putative EU tax schedules for A and $\mathrm{B}$ be $t_{A}(x)$ and $t_{B}(x)$ respectively, and let $v_{A}(x)=x-t_{A}(x)$ and $v_{B}(x)=x-t_{B}(x)$ be the respective post-EU-tax income functions. If by equal treatment we mean that those with the same pre-EU-tax living standard should also have the same post-EU-tax living standard, which is the usual criterion for classical horizontal equity, this requires the following property: $S\left(x_{B}\right)=x_{A} \Rightarrow v_{A}\left(x_{A}\right)=S\left(v_{B}\left(x_{B}\right)\right)$; or, writing $x_{B}$ as $x$ and substituting,

$$
S\left(v_{B}(x)\right)=v_{A}(S(x))
$$

That is, the living standard after tax of a citizen of country B having $x$ before the EU tax should be the same as that of a citizen of A having $S(x)$ before the EU tax. ${ }^{4}$ Setting $t_{A}(x)$ as the "reference" tax schedule in country A, which can embody any chosen degree of vertical equity, $t_{B}(x)$ would have to be designed to satisfy (1) in order that both horizontal and vertical equity be achieved by the overall income tax.

\footnotetext{
${ }^{4}$ If, on the other hand, 'equal treatment' would mean that pre-tax equals should experience equal average tax rates, the criterion would be $t_{A}(S(x)) / S(x)=t_{B}(x) / x$. If instead equal treatment were taken to mean equal tax payments, then $t_{A}(S(x))=t_{B}(x)$ would be the criterion. For more on these two, see Lambert (2004b).
} 
The result of Ebert and Lambert (2004) already referred to shows that if the equivalent income function takes the isoelastic form, $S(x)=(x / b)^{a}$ where $a>0$ and $b>0$ are constants, then when $t_{B}(x)$ is constructed so that the tax system $\left\{t_{A}(x), t_{B}(x)\right\}$ obeys (1), citizens of country B with a given pre-EU-tax living standard will face the same degree of progression as citizens of country A with that living standard. Thus, an extended concept of equity, equal progression among equals, is attainable in this case (and in fact, in only the isoelastic case). ${ }^{5}$

\section{Lognormality and positional equity}

It is perhaps an heroic assumption to make, that country-specific net income distributions within the EU are all lognormal. In fact, for what follows, the EU member income distributions may belong to some other family of distributions which in logarithms differ only by location and scale - such as the Pareto and Singh-Maddala families, for example. Again restricting attention expositionally to the case of two countries A and B, under the location and scale assumption an isoelastic function $x_{A}=S\left(x_{B}\right)$ exists which matches the incomes in $\mathrm{A}$ and $\mathrm{B}$ position by position. ${ }^{6}$ Taking the equals in the different EU countries to be those at the same percentile points, (1) can be used to specify an EU-wide layer of additional income tax which both assures equal treatment by percentile in the classical sense and also equal progression by percentile.

Putting $S(x)=(x / b)^{a}$ into (1), and taking $t_{A}(\mathrm{x})$ as given, the following formula for $v_{B}(x)$ results, in terms of $v_{A}(x)$ :

$$
v_{B}(x)=b \cdot\left[v_{A}\left(\left(\frac{x}{b}\right)^{a}\right)\right]^{\frac{1}{a}}
$$

In one special case, that in which $t_{A}(x)$ is proportional, $v_{A}(x)=\left(1-g_{A}\right) x$ say, it is clear from (2) that for equity, $t_{B}(x)$ should also be proportional:

\footnotetext{
5 See op cit. for further details, and also Dardanoni and Lambert (2002). The progression measure is residual progression, defined for a schedule $\mathrm{t}(\mathrm{x})$ as the elasticity of post-tax income $v(x)=x-t(x)$ with respect to pretax income, i.e. as $x v^{\prime}(x) / v(x)$.

${ }^{6}$ If $\ln \left(x_{A}\right) \approx N\left(\theta_{A}, \sigma_{A}^{2}\right)$ and $\ln \left(x_{B}\right) \approx N\left(\theta_{B}, \sigma_{B}^{2}\right)$, then, as the reader may verify, $S(x)=(x / b)^{a}$ matches incomes position by position for $a=\sigma_{A} / \sigma_{B}$ and $b=\exp \left\{\theta_{B}-a^{-1} \theta_{A}\right\}$.
} 


$$
v_{B}(x)=\left(1-g_{B}\right) x, \quad g_{B}=1-\left(1-g_{A}\right)^{1 / a}
$$

An EU-wide layer of differentiated proportional tax surcharges could thus be supported as fully equitable if $a \neq 1$. Proportional EU taxes would have the advantage of not interfering with relative income differentials within countries. They would have to be differentiated to the extent that inequality differed between countries. In the lognormal case, the flat tax rate would have to be higher in more unequal countries, and lower in less unequal countries. ${ }^{7}$

Whatever tax schedule is selected for country A, proportional or not, so long as it expresses the desired degree of vertical equity in country A, the tax for B is dictated by the equity requirement in (2), and this guarantees not only equal treatment by percentile in the classical sense but also equal progression by percentile across countries.

\section{Positional social welfare and equal sacrifice}

If the tax schedule chosen for country A by the EU tax designers is such that it engenders equal sacrifices within that country, according to a local (country A) social decisionmaker's imposed value judgement, does the tax schedule required by (2) to hold in country B also engender equal sacrifices as perceived within country B? This would be very pleasant, as it would allow the politicians in country B to ensure their country-folk that the tax they will have to pay has been well thought-out, but condition (2), for equity, is paramount; the answer to the equal sacrifice question depends entirely on the evaluation functions attributed by the social decision-makers in each country. We investigate this question now.

Despite the avowedly utilitarian nature of equal sacrifice analysis, Yaari (1988) has shown that the principle can also be articulated in terms of a rank-dependent (linear) social welfare function, in which case one's tax liability becomes a function of one's position in the distribution of income rather than one's income per se. Lambert and

\footnotetext{
7 From (3), $g_{B}>g_{A}$ if $a<1$ and $g_{B}<g_{A}$ if $a>1$. The case $a=1$ would yield a common proportional tax in both countries, see footnote 1 on this. Under the lognormality assumption, the Lorenz curves for A and B do not intersect if $\sigma_{A} \neq \sigma_{B}$, i.e. if $a \neq 1$. Setting $a=\sigma_{A} / \sigma_{B}$ as in footnote 6 , we have $g_{B}>g_{A}$ if $\sigma_{A}<\sigma_{B}$ and $g_{B}<g_{A}$ if $\sigma_{A}>\sigma_{B}$. A minor error in Lambert (2004a) led to this relationship being incorrectly described there.
} 
Naughton (2006) extend the equal sacrifice prescription to a class of mixed utilitarian and rank-dependent social welfare functions, which invoke a social utility-of-income function and also attribute weights giving systematically differing social importance to different people's positions in the income distribution. In such a case, tax liability is a function of both one's income and one's position. This model seems to be worth investigating in the EU context, given the positional equity criterion already articulated.

The Lambert and Naughton (2006) analysis is based upon a doubly parametric family of social evaluation functions of the form

$$
Z_{X}(e, v)=\int_{0}^{\infty} U_{e}(x) \varphi_{v}^{\prime}(F(x)) f(x) d x
$$

where $\alpha>0, U_{e}(x)=\alpha \frac{x^{1-e}}{1-e}, 0 \leq e \neq 1, U_{1}(x)=\alpha \ln (x), \varphi_{v}(p)=1-(1-p)^{v}, 0 \leq p \leq 1$, $v \geq 1$ and $F(x)$ is the distribution function for taxable income. These are "mixed" utilitarian and rank-dependent social welfare functions, as originally introduced by Berrebi and Silber (1981) and further developed by Araar and Duclos $(2003,2005){ }^{8}$ The special case $v=1$ generates the utilitarian SWF popularized by Atkinson in his 1970 paper and presaged in the work of $\operatorname{Kolm}(1965,1968,1969)$. The special case $e=0$ is that of the Yaari (1988) linear and rank-dependent SWF.

An equal sacrifice tax function $t(x)$ for this social evaluation function takes the form

$$
t(x)=x-\left[x^{1-e}-\frac{c(1-e)}{v[1-F(x)]^{v-1}}\right]^{1 / 1-e} \quad \forall x \in\left[x_{0}, x_{1}\right]
$$

if $e \neq 1$, and

$$
t(x)=\left[1-\exp \left\{-c / v[1-F(x)]^{v-1}\right\}\right] x \quad \forall x \in\left[x_{0}, x_{1}\right]
$$

\footnotetext{
${ }^{8}$ See also Ebert (1988, pp. 155-156), where rank-dependent SWFs are developed which are respectively linear and concave in incomes. In Ebert and Welsch (2004), the "Atkinson-Gini family" of SWFs is also considered, the aim being to fit parameter estimates to the preferences of a "representative European individual" on the basis of happiness data in the Eurobarometer survey series. For the genesis of a more general class of "rank-dependent expected utility" (RDEU) evaluation functions, of the form $Z=\int_{0}^{\infty} U(x) \varphi^{\prime}(F(x)) f(x) d x$ where $U(x)$ and $\varphi(p)$ are both concave, the reader may consult Quiggin (1993), chapters 5 and 14 .
} 
when $e=1$, for some $x_{0} \geq 0$ and, unless $v=1$, for some $x_{1}$ such that $F\left(x_{1}\right) \neq 1$ (if $v=1$ then $x_{1} \rightarrow \infty$ ), where the per-person sacrifice is $\alpha c$. Unless $v=1$, this tax depends on both income and percentile. When $v=1,(5 a)$ and $(5 b)$ yield the well-known solution to the classical equal sacrifice criterion $U_{e}(x)-U_{e}(x-t(x)) \equiv \alpha c \forall x \geq x_{0}$ (see Young, 1990, for example), and when $e=0,(5 a)$ reduces to $t(x)=\frac{c}{v[1-F(x)]^{v-1}} \forall x \in\left[x_{0}, x_{1}\right]$ with $x_{0}>\frac{c}{v}$, which is in fact the Yaari (1988) prescription. ${ }^{9}$

\section{Value judgements for positional equity and equal sacrifice}

Let the social evaluation function in country $\mathrm{A}$ be $Z_{A}(e, v)$ defined as in (4), in which the utility function is $U_{A}(x)=\alpha_{A} \cdot \frac{x^{1-e}}{1-e}$ if $0 \leq e \neq 1, U_{A}(x)=\alpha_{A} \cdot \ln (x)$ if $e=1$, and the distribution function for taxable incomes is $F_{A}\left(\right.$.). Let the tax schedule $t_{A}(x)$ in country A be defined by (5a) or (5b). As already explained, for equity the tax schedule $t_{B}(x)$ in country $\mathrm{B}$ is defined by substituting $t_{A}(x)$ into (2), obtaining: $v_{B}\left(x_{B}\right)=b \cdot\left[v_{A}\left(x_{A}\right)\right]^{1 / a}$ $=b \cdot\left[x_{A}-t_{A}\left(x_{A}\right)\right]^{1 / a}$ or, from (5a)-(5b), $v_{B}\left(x_{B}\right)=b \cdot\left[x_{A}^{1-e}-\frac{c(1-e)}{v\left[1-F_{A}\left(x_{A}\right)\right]^{v-1}}\right]^{1 / a(1-e)}$ if $e \neq 1$, and $v_{B}\left(x_{B}\right)=b \cdot \exp \left\{-c / a v\left[1-F_{A}\left(x_{A}\right)\right]^{v-1}\right\} x_{A}^{1 / a}$ if $e=1$. Because of the

\footnotetext{
${ }^{9}$ As $e$ and $v$ increase, the interval between the two cut-offs $x_{0}$ and $x_{l}$ dictated by admissibility of the equal sacrifice prescription becomes smaller and smaller. The cut-offs $x_{0}$ and $x_{1}$ provide a 'floor' and a 'ceiling' for the average tax rate profile but bring 'cusps' into the tax level/income relationships: see Lambert and Naughton (2006) for further details. The presence of these cut-offs does not mean that tax liabilities will be zero at the bottom and top. Some prescription other than equal sacrifice would have to guide such taxes, and would, of course, have to be taken into account in determining the revenue consequences of the tax system. Early writers, from Carver (1895) onwards, were content to have the equal sacrifice principle applied over a bounded range. Young (1990) found that his equal sacrifice model did not fit in the tails of the US income distribution. For $e=1$ (only), the equal sacrifice tax liability itself actually decreases with income, from approximately the median onwards. If $\mathrm{e}<1$, the restriction $x_{0} \cdot\left[1-F\left(x_{0}\right)\right]^{(v-1) /(1-e)}>\left[\frac{c(1-e)}{v}\right]^{1 / 1-e}$ on $x_{0}$ is implied.
} 
percentile matching criterion, if $F_{B}($.$) is the distribution function for pre-tax incomes in$ country B, then $F_{A}\left(x_{A}\right)=F_{B}\left(x_{B}\right)$ where $x_{A}=S\left(x_{B}\right)=\left(\frac{x_{B}}{b}\right)^{a}$. This means that $t_{B}(x)$ is defined as follows:

$$
t_{B}\left(x_{B}\right)=x_{B}-\left[x_{B}^{a(1-e)}-\frac{b^{a(1-e)} c(1-e)}{v\left[1-F_{B}\left(x_{B}\right)\right]^{v-1}}\right]^{1 / a(1-e)}
$$

if $e \neq 1$, and

$$
t_{B}\left(x_{B}\right)=\left[1-\exp \left\{-c / a v\left[1-F_{\mathrm{B}}\left(x_{B}\right)\right]^{v-1}\right\}\right] x_{B}
$$

when $e=1$. The per capita sacrifice in country $\mathrm{A}$ is $\alpha_{A} c$.

What does it take in order that this "induced" tax $t_{B}(x)$ also be an equal sacrifice tax, for a social evaluation function in country B like the one in country A, but with parameters $\tilde{c}, \tilde{e}$ and $\tilde{v}$, say?

For equal sacrifices of $\alpha_{B} \tilde{c}$ per capita in country $\mathrm{B}$, according to an evaluation function $Z_{B}(\tilde{e}, \tilde{v})$ defined as in (4), but with utility-of-income function $U_{B}(x)=\alpha_{B} \cdot \frac{x^{1-\tilde{e}}}{1-\tilde{e}}$ if $0 \leq \tilde{e} \neq 1$, and $U_{B}(x)=\alpha_{B} \cdot \ln (x)$ if $\tilde{e}=1$, from (5a)-(5b) we must have

$$
t_{B}\left(x_{B}\right)=x_{B}-\left[x_{B}{ }^{1-\tilde{e}}-\frac{\tilde{c}(1-\tilde{e})}{\tilde{v}\left[1-F_{B}\left(x_{B}\right)\right]^{\tilde{v}-1}}\right]^{1 / 1-\tilde{e}}
$$

if $\tilde{e} \neq 1$, and

$$
t_{B}\left(x_{B}\right)=\left[1-\exp \left\{-\tilde{c} / \tilde{v}\left[1-F_{B}\left(x_{B}\right)\right]^{\tilde{v}-1}\right\}\right] x_{B}
$$

when $\tilde{e}=1$ (with end-of-range restrictions which we shall simply assume from now on). Comparing (7a)-(7b) with (8a)-(8b), the following result is fairly immediate.

\section{Theorem}

If $v=\tilde{v}, 1-\tilde{e}=a(1-e)$ and $\tilde{c}=c \cdot b^{1-\tilde{e}} / a$, then (7) and (8) are equivalent. 
Under the conditions on social evaluation functions expressed in this theorem, the rank weighting scheme in country $\mathrm{B}$ is the same as that in country $\mathrm{A}(v=\widetilde{v})$, the inequality aversion parameters of the respective utility of income functions differ, and the per capita sacrifice levels $\alpha_{A} c$ and $\alpha_{B} \tilde{c}$ are related in this way:

$$
\frac{\alpha_{A} c}{\alpha_{B} \tilde{c}}=\frac{U_{A}\left(x_{A}\right)}{U_{B}\left(x_{B}\right)}=\frac{U_{A}\left(S\left(x_{B}\right)\right)}{U_{B}\left(x_{B}\right)} \quad \forall x_{B}
$$

so that the proportional sacrifice is the same for equals in the two countries. If $a=b=1$, the income distributions in A and B are identical and so are the tax functions. In general, the relationship between the tax schedules $t_{A}(x)$ and $t_{B}(x)$, and the per capita sacrifice levels $\alpha_{A} c$ and $\alpha_{B} \tilde{c}$, depends on both the shift in location and the shift in scale of the distribution of income in $\mathrm{B}$ (in logarithms) away from that in $\mathrm{A} .^{10}$

A restriction must apply in order that the $\tilde{e}$ of Theorem 1 be non-negative in case $e<1$. It is that

$$
\mathrm{a}<(1 / 1-e)
$$

If inequality is very low in region B (so that $a=\sigma_{A} / \sigma_{B}$ is very large), then (10) may be violated for some values of $e<1$. In fact, given $\sigma_{A}$ and $\sigma_{B}>\sigma_{A}$, $e>1-1 / a=\left(\sigma_{A}-\sigma_{B}\right) / \sigma_{A}$ is required. This tells us that the equal sacrifice model cannot apply in both countries if inequality aversion in the relatively very equal country B is not sufficiently close to unity. In the case of $\mathrm{n}$ countries, $\mathrm{A}$ and $\mathrm{B}_{\mathrm{i}}, i=1,2, \ldots \mathrm{n}-1$, where from Theorem 1 the inequality aversions $\tilde{e}_{i}$ satisfy

$$
1-\tilde{e}_{i}=a_{i}(1-e) \text { where } a_{i}=\sigma_{A} / \sigma_{B_{i}}
$$

the model fails to prescribe equal sacrifice taxes in all countries unless

$$
e>\max \left\{1-\frac{1}{a_{1}}, 1-\frac{1}{a_{2}}, \ldots 1-\frac{1}{a_{n-1}}\right\}
$$

\footnotetext{
${ }^{10}$ As Lambert and Naughton (2006) show for this equal sacrifice model, there is a one-to-one relationship between the per capita sacrifice level and the revenue raised by the tax.
} 
If (12) does hold, then the following is implied by (11): if $0<e<1$, inequality aversion $\tilde{e}_{i}(<1)$ will be lower the higher is $a_{i}$ (i.e. the lower is inequality in country $\mathrm{B}_{\mathrm{i}}$ ), whilst if $e>1$, inequality aversion $\tilde{e}_{i}(>1)$ will be higher the higher is $a_{i}$ (i.e. the lower is inequality in country $\mathrm{B}_{\mathrm{i}}$ ). We have not seen such links suggested between inequality and inequality aversion in any other literature. ${ }^{11}$

\section{Positionally equitable equal sacrifice taxes in the EU: some illustrative calculations}

Let $\mathrm{p}$ be the rank of a person in country A with income $x_{A}$, and let the income of a person in country B with rank $\mathrm{p}$ be $x_{B}$, where, of course, $x_{A}=\left(x_{B} / b\right)^{a}$ and $p=F_{A}\left(x_{A}\right)=F_{B}\left(x_{B}\right)$. Denote $A T R_{A}(p)=t_{A}\left(x_{A}\right) / x_{A}$ and $A T R_{B}(p)=t_{B}\left(x_{B}\right) / x_{B}$ as the average tax rates at percentile $\mathrm{p}$ in the two countries. It follows either from (2), or by substituting parameter values from Theorem 1 into (8a)-(8b) and comparing with (5a)-(5b), that

$$
\left[1-A T R_{A}(p)\right]=\left[1-A T R_{B}(p)\right]^{a}
$$

so that average tax rates are not the same at corresponding positions in the two distributions (recall footnote 4 on this). Equation (13) can be used use to compute average tax rates at given percentile points in $\mathrm{B}$ from information about distribution $\mathrm{A}$ and its tax schedule (this is not necessary if $e=1$, as the average tax rate in each country is flat in this case). Thus let $u(p)$ denote the value in $N(0,1)$ at percentile point $p$, so that $x_{A}=\exp \left\{\theta_{A}+u(p) \sigma_{A}\right\}$ is the income level at percentile $p$ in country A. Assuming $e \neq 1$, from (5a) we have

$$
\operatorname{ATR}_{A}(p)=1-\left[1-\frac{c(1-e)}{v \cdot \exp \left\{(1-e)\left(\theta_{A}+u(p) \sigma_{A}\right)\right\}(1-p)^{v-1}}\right]^{1 / 1-e}
$$

\footnotetext{
${ }^{11}$ One might wish that the model would validate a lower concern for inequality in countries where inequality is lower, but this is clearly not the case: a positive association between $\left|1-\tilde{e}_{i}\right|$ and $\sigma_{B_{i}}$ is suggested, given $\sigma_{A}$. Atkinson (1970, p. 251) argues for higher inequality aversion in richer counties: "it might quite reasonably be argued that as the general level of income rises we are more concerned about inequality," whilst Lambert et al. (2003) find a tendency for inequality aversion and inequality to move in opposite directions between countries "...the inference that relatively inequality averse countries have lower levels of objective inequality appears robust” (see also Harvey, 2005, on this).
} 
and then $A T R_{B}(p)$ follows from (13). If we set $c$ such that the average tax rate on the median income in country $\mathrm{A}$ is $\lambda$, say, then (14) requires that $c=\frac{v \cdot \exp \left\{(1-e)\left(\theta_{A}+u\left(\frac{1}{2}\right) \sigma_{A}\right\} \cdot\left(\frac{1}{2}\right)^{v-1}\right.}{(1-e)} \cdot\left[1-(1-\lambda)^{1-e}\right]$, where of course $u\left(\frac{1}{2}\right)=0$, and in consequence (14) itself becomes

$$
\operatorname{ATR}_{A}(p)=1-\left[1-\frac{1-(1-\lambda)^{1-e}}{\exp \left\{(1-e) \sigma_{A} u(p)\right\} \cdot[2(1-p)]^{v-1}}\right]^{1 / 1-e} \quad(\mathrm{e} \neq 1)
$$

which is readily computed in terms of $p, e, v$ and $\lambda$,along with the lognormal parameter $\sigma_{A}$. If $e=1$, then from (5b), $c=v \cdot\left(\frac{1}{2}\right)^{v-1} /(1-\lambda)$ is required and then

$$
A T R_{A}(p)=1-(1-\lambda)^{1 /[2(1-p)]^{v-1}} \quad(e=1)
$$

In order to compute the average tax rate in $\mathrm{B}$ at percentile $p$ we use (13); the only additional information we need is the relativity parameter $a=\sigma_{A} / \sigma_{B}$. To compute the average tax rate in A or B at a fixed income level, $\tilde{x}$ say, first we identify the relevant percentile points for that income level in $\mathrm{A}$ and $\mathrm{B}$, call them $\tilde{p}_{A}$ in $\mathrm{A}$ and $\tilde{p}_{B}$ in $\mathrm{B},{ }^{12}$ and then we use (15a)-(15b) to compute $A T R_{A}\left(\tilde{p}_{A}\right)$ (and also $\left.A T R_{A}\left(\tilde{p}_{B}\right)\right)$ and (13) to obtain $A T R_{B}\left(\tilde{p}_{B}\right)$ (in terms of $A T R_{A}\left(\tilde{p}_{B}\right)$ ).

We now give some illustrative calculations to show how the additional layer of income tax might impact upon income units in countries of the old EU with high and low mean incomes and high and low inequality, and upon new member countries and candidate countries too.

Table I shows the mean of logarithms $\theta$ (in nominal euros) and variance of logarithms $\sigma^{2}$ for net annual earnings in six EU countries for the year 2000, using

${ }^{12}$ These points can be identified from the equations $u\left(\tilde{p}_{A}\right)={ }^{\left[\ln (\tilde{x})-\theta_{A}\right]} / \sigma_{A}$ and $u\left(\tilde{p}_{B}\right)={ }^{\left[\ln (\tilde{x})-\theta_{B}\right]} / \sigma_{B}$ and the $\mathrm{N}(0,1)$ distribution. Notice that $u\left(\tilde{p}_{B}\right)=a \cdot u\left(\tilde{p}_{A}\right)+\frac{1}{\sigma_{A}}\left[(a-1) \theta_{A}-a \ell n(b)\right]$ 
estimates kindly supplied by Panos Tsakloglou, ${ }^{13}$ along with the mean incomes $\mu$ for those countries, computed according to the lognormality assumption as $\mu=\exp \left\{\theta+\frac{1}{2} \sigma^{2}\right\} .^{14}$

Table 1: approximate lognormal parameters $\theta$ and $\sigma^{2}$ for the distributions of net annual incomes in six EU countries for the year 2000, along with the means $\mu$

$\begin{array}{llll}\text { Luxembourg } & \theta=9.771 & \sigma^{2}=0.296 & \mu=20,312 \\ \text { Denmark } & \theta=9.566 & \sigma^{2}=0.245 & \mu=16,131 \\ \text { UK } & \theta=9.448 & \sigma^{2}=0.399 & \mu=15,483 \\ \text { Spain } & \theta=8.698 & \sigma^{2}=0.346 & \mu=7,122 \\ \text { Greece } & \theta=8.400 & \sigma^{2}=0.375 & \mu=5,364 \\ \text { Portugal } & \theta=8.289 & \sigma^{2}=0.377 & \mu=4,805\end{array}$

In order to proceed with stylized calculations, representing putative member countries of the EU but not actual ones dependent on these specific estimates, we select representative "high" and "low" values for the lognormal parameters, namely these:

$$
\theta_{L}=8.3, \quad \theta_{H}=9.8, \quad \sigma_{L}^{2}=0.25, \quad \sigma_{\mathrm{H}}^{2}=0.40
$$

Taking combinations of these parameters, we obtain four putative distributions exhibiting high(H)/low(L) mean of logarithms and high(H)/low(L) variance of logarithms, which we may call HH, HL, LH, LL (clearly Luxembourg and Denmark could be represented by HL, and the UK by HH, but low inequality does not occur along with a low mean in this data; the other three countries cited are much closer to LH than LL). New and

13 In Tsakloglou and Cholezas (2005) and Cholezas and Tsakloglou (2007), the mean and the variance of logarithms of hourly net earnings in 2000 in 13 of the original 15 EU countries can be found, computed from the final wave of the European Community Household Panel (ECHP) for 2001, where the income reference year is 2000. These summary statistics do not relate to overall net incomes, however, on account of missing components such as unearned incomes, and also because hours worked vary between countries (see ibid.). The figures quoted in Table 1 are for annual net incomes from all sources, but excluding individuals whose total such income is less than 1,000 euros per year (because the variance of logarithms is very sensitive to extremely low income values). We thank Panos Tsakloglou for supplying the tabulations from which these six sets of estimates are drawn.

${ }^{14}$ The ranking of the countries in Table 1 in terms of means accords with that of the OECD for real GDP per head in 2002. See Eurostat (2004), in which Luxembourg is characterized as a high income country, Denmark is near the top of the high-middle income group, the UK is a little further down in that group, Spain is at the top of the low-middle income group, and Greece and Portugal are in the middle of that group. 
candidate countries of the EU generally have lower per capita income levels, but similar inequality experiences as the older member states. ${ }^{15}$ An "ultra-low" $\theta$-value, in combination with the already-set high and low $\sigma^{2}$-values can be used to represent such countries. We chose

$$
\theta_{U}=8.0
$$

for this purpose, giving rise to two new constellations UL and UH (which could represent Croatia and Latvia respectively, for example) to join the existing four.

Taking HH as country A, the parameters $a_{i}=\sigma_{A} / \sigma_{B_{i}}$ and $b_{i}=\exp \left\{\theta_{B_{i}}-a_{i} \theta_{A}\right\}, i$ $=\mathrm{LH}, \mathrm{HL}, \mathrm{LL}, \mathrm{UH}, \mathrm{UL}$ can now be calculated. Here are the relevant values:
$\mathrm{HH}: a_{H H}=1, b_{H H}=1$
LH: $a_{L H}=1, b_{L H}=\exp \left\{\theta_{L}-a_{L H}{ }^{-1} \theta_{H}\right\}=\exp \{8.3-9.8\}=0.223$
HL: $a_{H L}=1.6, \quad b_{H L}=\exp \left\{\theta_{H}-a_{H L}{ }^{-1} \theta_{H}\right\}=\exp \left\{9.8-\left(1.6^{-1} \times 9.8\right)\right\}=39.449$
LL: $a_{L L}=1.6, \quad b_{L L}=\exp \left\{\theta_{L}-a_{L L}{ }^{-1} \theta_{H}\right\}=\exp \left\{8.3-\left(1.6^{-1} \times 9.8\right)\right\}=8.802$
$\mathrm{UH}: a_{U H}=1, \quad b_{U H}=\exp \left\{\theta_{U}-a_{U H}{ }^{-1} \theta_{H}\right\}=\exp \{8.0-9.8\}=0.165$
$\mathrm{UL}: a_{U L}=1.6, b_{U L}=\exp \left\{\theta_{U}-a_{U L}{ }^{-1} \theta_{H}\right\}=\exp \left\{8.0-\left(1.6^{-1} \times 9.8\right)\right\}=6.521$

We shall not need the $b_{i}$-values for the calculation of average tax rates at percentiles (recall (13) and (15a)-(15b)). We set $v=1,2$ (representing the utilitarian and Gini-based mixed SWF respectively), and choose $e=\frac{1}{2}, 1,2$ as the inequality aversion parameter in country $\mathrm{HH}$ (equal to that in the other high-inequality countries, from (11), from which it also follows that inequality aversion in the low-inequality countries has to be $\tilde{e}=0.2,1,2.6$ for coherence with the model).

Table 2 shows average tax rate by percentile in each of the six constellations in the case that $\lambda=0.01$, i.e. when the average tax rate at median income in country $\mathrm{HH}$ is set at $1 \%$. Table 3 shows average tax rates in the six constellations at fixed income values

15 Take for example Latvia and Croatia as examples of new and candidate EU countries. In World Development Indicators (2006), GDP per capita and Gini coefficient values can be found for very many countries including these two and of course all of the countries of the old EU. Variances of logs are absent from these statistics unfortunately, but the Ginis suggest that Latvia's inequality lies between that of Portugal and the UK, and that Croatia's is close to that of Denmark. In respect of the means (and broadly in accord with Eurostat, 2004, already cited), Latvia in 2003 had a real GDP per head of about $1 / 5^{\text {th }}$ of that in Luxembourg, and Croatia fared slightly better. 
(for which the $b_{i}$-values are used to compute the appropriate positions $\tilde{p}_{i}$, recall footnote $11)$.

Table 2: \% average tax rates at given percentiles for the six constellations

\begin{tabular}{|c|c|c|c|c|c|c|c|}
\hline percentile & $20 t h$ & 30 th & 40th & $50 t h$ & $60 t h$ & $70 t h$ & 80th \\
\hline$v=1 \quad$ (utilitarian $)$ & & & & & & & \\
\hline$e=\frac{1}{2}$ & & & & & & & \\
\hline HH, LH, UH & 1.30 & 1.18 & 1.08 & 1.00 & 0.92 & 0.85 & 0.77 \\
\hline HL, LL, UL & 0.70 & 0.63 & 0.58 & 0.54 & 0.49 & 0.45 & 0.41 \\
\hline$e=1$ & & & & & & & \\
\hline HH, LH, UH & 1.00 & 1.00 & 1.00 & 1.00 & 1.00 & 1.00 & 1.00 \\
\hline HL, LL, UL & 0.54 & 0.54 & 0.54 & 0.54 & 0.54 & 0.54 & 0.54 \\
\hline$e=2$ & & & & & & & \\
\hline $\mathrm{HH}, \mathrm{LH}, \mathrm{UH}$ & 0.59 & 0.72 & 0.85 & 1.00 & 1.17 & 1.39 & 1.69 \\
\hline HL, LL, UL & 0.32 & 0.39 & 0.46 & 0.54 & 0.63 & 0.74 & 0.91 \\
\hline$v=2($ Gini-based $)$ & & & & & & & \\
\hline$e=\frac{1}{2}$ & & & & & & & \\
\hline HH, LH, UH & 0.82 & 0.84 & 0.90 & 1.00 & 1.15 & 1.41 & 1.91 \\
\hline HL, LL, UL & 0.44 & 0.45 & 0.48 & 0.54 & 0.62 & 0.76 & 1.03 \\
\hline$e=1$ & & & & & & & \\
\hline $\mathrm{HH}, \mathrm{LH}, \mathrm{UH}$ & 1.59 & 1.40 & 1.20 & 1.00 & 0.80 & 0.60 & 0.40 \\
\hline HL, LL, UL & 0.86 & 0.75 & 0.64 & 0.54 & 0.43 & 0.32 & 0.21 \\
\hline$e=2$ & & & & & & & \\
\hline HH, LH, UH & 0.37 & 0.52 & 0.71 & 1.00 & 1.46 & 2.29 & 4.12 \\
\hline HL, LL, UL & 0.20 & 0.28 & 0.38 & 0.54 & 0.78 & 1.23 & 2.23 \\
\hline
\end{tabular}

As Table 2 shows, the utilitarian equal sacrifice tax is regressive when $e=\frac{1}{2}$. In fact this would be so for any $e<1$ : see Young (1990). Also the tax is regressive when $e=$ 1 in the Gini-based case: see Lambert and Naughton (2006) on this. Notice that in all cases the average tax rate at the median is $1 \%$ in high inequality constellations and $0.54 \%$ in low inequality constellations (and these are the flat rates at all percentiles if $v=e=1$ ). The tax rate at given percentiles depends only on inequality - there is no discrepancy between these tax rates in the high, low and ultra-low mean constellations. For $v=2$, the average tax rate rises much faster along the income parade when $e=2$ than when $e=\frac{1}{2}$, but starts from a lower base. 
Table 3: \% average tax rates at given income values (expressed in terms of $\mathrm{HH}$ percentile) for the six constellations

\begin{tabular}{lcccccc} 
Income value, by & \multicolumn{7}{c}{ \% average tax rate at that income value } \\
percentile in $H H$ & $H H$ & $H L$ & $L H$ & $L L$ & $U H$ & $U L$ \\
& & & & & & \\
$v=1, e=2$ & & & & & & \\
at $20^{\text {th }}$ in $\mathrm{HH}$ & 0.59 & 0.32 & 2.59 & 35.45 & 3.47 & 99.89 \\
at $30^{\text {th }}$ in $\mathrm{HH}$ & 0.72 & 0.38 & 3.15 & 39.53 & 4.21 & 99.91 \\
at $40^{\text {th }}$ in $\mathrm{HH}$ & 0.85 & 0.44 & 3.72 & 43.15 & 4.96 & 99.92 \\
at $50^{\text {th }}$ in $\mathrm{HH}$ & 1.00 & 0.50 & 4.33 & 46.60 & 5.77 & 99.93 \\
at $60^{\text {th }}$ in $\mathrm{HH}$ & 1.17 & 0.57 & 5.04 & 50.07 & 6.70 & 99.94 \\
at $70^{\text {th }}$ in $\mathrm{HH}$ & 1.39 & 0.66 & 5.94 & 53.81 & 7.86 & 99.95 \\
at $80^{\text {th }}$ in $\mathrm{HH}$ & 1.69 & 0.77 & 7.16 & 58.09 & 9.44 & 99.96 \\
$v=2, e=2$ & & & & & & \\
$v=2$, & & & & & & \\
at $20^{\text {th }}$ in $\mathrm{HH}$ & 0.37 & 0.20 & 1.64 & 25.56 & 2.20 & 99.82 \\
at $30^{\text {th }}$ in $\mathrm{HH}$ & 0.52 & 0.27 & 2.27 & 31.83 & 3.04 & 99.87 \\
at $40^{\text {th }}$ in $\mathrm{HH}$ & 0.71 & 0.37 & 3.12 & 38.75 & 4.17 & 99.91 \\
at $50^{\text {th }}$ in $\mathrm{HH}$ & 1.00 & 0.50 & 4.33 & 46.60 & 5.77 & 99.93 \\
at $60^{\text {th }}$ in $\mathrm{HH}$ & 1.46 & 0.71 & 6.23 & 55.63 & 8.24 & 99.99 \\
at $70^{\text {th }}$ in $\mathrm{HH}$ & 2.29 & 1.05 & 9.52 & 66.00 & 12.45 & 99.99 \\
at $80^{\text {th }}$ in $\mathrm{HH}$ & 4.12 & 1.73 & 16.16 & 77.60 & 20.67 & 99.99
\end{tabular}

Table 3 compares the tax rates which would be experienced at fixed income levels in the different constellations. The fixed income levels chosen for these comparisons are those to be found at the $20^{\text {th }}$ to $80^{\text {th }}$ percentile points in constellation $\mathrm{HH}$. Comparing $\mathrm{HH}$ with HL, we see that among the richer countries of the EU, those with less inequality have lower tax rates at any given income level. The constellations LH and UH could represent poorer old EU countries and new ones, for example Portugal and Latvia. Taxpayers in these countries can expect to pay higher taxes than those living in the richer countries at the same income level (though not at the same percentile, as we have already observed). The tax rates in LL and UL are extraordinarily high. We do not have LL countries presently in the EU, but Croatia is a candidate EU country which may be in the UL category. Of course, the combination of a low or ultra-low mean and low inequality implies that the income values in constellations LL and UL which correspond to many of the decile values quoted in Table 3 for $\mathrm{HH}$ will be right at the top, where the density of taxpayers is extremely thin - and the equal sacrifice model in any case breaks down at very high percentiles (as stated in equations (5a)-(5b), see also footnote 9 ). 
Finally, we turn to the Luxembourg/Latvia question in terms of which we opened this whole discussion. A net annual income of $€ 20,000$ is close to the mean in Luxembourg and at approximately the $65^{\text {th }}$ percentile on the basis of the figures in Table 1 , and at approximately the $75^{\text {th }}$ percentile in the UK (our representative of constellation $\mathrm{HH})$. Taking Latvia to be represented by $\theta_{U}$ and $\sigma_{H}$, a net annual income of $€ 20,000$ would be more than 5 times the Latvian mean and in the very top percentile. We see from Table 3 that the additional layer of income tax across the EU, if designed to satisfy positional equity and equal sacrifice, could lead to tax rates of the order of $1 \frac{1}{2} \%-3 \%$ in the UK, $0.7 \%-1 \frac{1}{2} \%$ in Luxembourg and $8 \%-15 \%$ in Latvia on an annual disposable income of $€ 20,000$ (depending on parameter values, and assuming a $1 \%$ tax on the median UK income).

A much-debated issue in present-day political philosophy is whether redistribution should be kept within nations or go beyond. The debate was started by Rawls (1993), who argued that it should be kept within Nation-States. The European Union is of course not a Nation-State, but is acquiring some of the features of one. Would it become one, then it could be seen as a "community of redistribution" in Kolm's (2004) language, a "federal polity" in Buchanan's (1950) terms. For Buchanan, similarly situated individuals in different EU member countries should then have equivalent overall "fiscal residua" (p.568), i.e. the value of public services provided by the EU, as well as by the member countries, would have to be taken into account in formulating an equal treatment criterion (which our criterion (2) does not attempt to do). For Kolm (2004), a degree of redistribution would be established across the EU reflecting what is politically and socially possible and desired in this community. Kolm would foresee a process according to which, as a European sense of community progressively develops, a degree of redistribution in between full equalization and no redistribution at all would emerge and evolve dynamically. The parameter $\lambda$, which in our model specifies the percentage tax rate on the median income in the reference country A (constellation $\mathrm{HH}$ in the empirical illustration), and fully determines the entire profile of taxes given the value judgement and distributional parameters, could be adjusted upwards from a much lower starting point than the $1 \%$ we have assumed, to reflect such an evolution. 
If fiscal equity across the EU called for equal average tax rates on net incomes across member countries, rather than equal treatment in the sense of (2), then of course none of the analysis of this paper would apply (as we said in footnote 4). We have conditioned the analysis on a positional equity criterion, according to which the equals in different EU countries are those at the same percentile points in the country-specific income distributions. We also assumed that the country-specific income distributions differ in logarithms by location and scale only. Our illustrative calculations have shown that, under these assumptions, it would be feasible to design an EU income tax which would engender both equal progression among equals and equal sacrifices from the citizens of each country in terms of rank-dependent and utilitarian social evaluation functions. Moreover, under the scheme advocated, each person experiences the same proportionate utility-of-income sacrifice as his or her peers in the other EU countries. The way is now open for a deeper and more careful study, should the issue of the direct taxation of EU citizens actually reach the political agenda.

\section{References}

Araar, A. and J.-Y. Duclos (2003). An Atkinson-Gini family of social evaluation functions. Economics Bulletin, vol. 3, no. 19, pp. 1-16.

Araar, A. and J.-Y. Duclos (2005). An Atkinson-Gini class of social evaluation functions: theory and illustration using data from the Luxembourg Income Study. LIS Working Paper No. 416, Syracuse University.

Atkinson, A.B. (1970). On the measurement of inequality. Journal of Economic Theory, vol. 2, pp. 244-263.

Berrebi, Z.M. and J. Silber (1981). Weighting income ranks and levels: a multi-parameter generalisation for absolute and relative inequality indices. Economics Letters, vol. 7, pp. 391-397.

Buchanan, J.M. (1950). Federalism and fiscal equity. American Economic Review, vol. 40, pp. 583-599.

Carver, T.N. (1895). The ethical basis of distribution and its application to taxation. Annals of the American Academy of Political and Social Science, vol. 6, pp. 79-99.

Cholezas, I. and P. Tsakloglou (2007). Earnings inequality in Europe: structure and pattern of intertemporal change. IZA Discussion Paper No. 2636, Berlin.

Cnossen, S. (2002). Tax policy in the European Union: a review of issues and options. FinanzArchiv: Public Finance Analysis, vol. 58, no. 4, pp. 466-558.

Cubel, M. and P.J. Lambert (2002a). Progression-neutral income tax reforms and horizontal inequity. Journal of Economics, vol. 9 (supplement), pp. 1-8. (Special issue 
entitled Inequalities, Measurement and Applications, edited by P. Moyes, C. Seidl and A.F. Shorrocks).

Cubel, M. and P.J. Lambert (2002b). A regional approach to income tax policy. Public Finance Review, vol. 30, pp. 124-143.

Dardanoni, V. and P.J. Lambert (2002). Progressivity comparisons. Journal of Public Economics, vol. 86, p. 99-122.

Ebert, U. (1988). Measurement of inequality: an attempt at unification and generalization. Social Choice and Welfare, vol. 5, pp. 147-169.

Ebert, U. (2000). Equivalizing incomes: a normative approach. International Tax and Public Finance, vol. 7, pp. 619-640.

Ebert, U. and P.J. Lambert (2004). Horizontal equity and progression when equivalence scales are not constant. Public Finance Review, vol. 32, pp. 426-440.

Ebert, U. and H. Welsch (2004). The Social Evaluation of Income Distribution: An Assessment Based on Happiness Surveys. LIS Working Paper No. 381, Syracuse University.

Eurostat (2004). Purchasing power parities and related economic indicators for the EU, candidate countries and EFTA" Statistics in Focus, No. 53

Harvey, J. (2005). A note on the 'natural rate of subjective inequality' hypothesis and the approximate relationship between the Gini coefficient and the Atkinson index. Journal of Public Economics, vol. 89, pp. 1021-1025.

Kolm, S.-C. (1965). The optimal production of social justice. Proceedings, International Economic Association Conference on Public Economics, Biarritz, France.

Kolm, S.-C. (1968). La production optimale de justice sociale. Pages 109-177 in J. Margolis and H. Guitton (eds.) Economie Publique. Paris: Editions du Centre National de la Recherche Scientifique, 1968.

Kolm, S.-C. (1969). The optimal production of social justice. Chapter 7, pages 145-200, in J. Margolis and H. Guitton (eds.) Public Economics: An Analysis of Public Production and Consumption and their Relations to the Private Sectors. London: Macmillan. Retypeset and republished as chapter 31, pages 606-649, in M. Blaug (ed.) The Foundations of $20^{\text {th }}$ Century Economics : Landmark Papers in General Equilibrium, Social Choice and Welfare, selected by Kenneth J. Arrow and Gérard Debreu. Cheltenham UK and Northampton MA: Edward Elgar, 2001. Relevant sections republished in 2007 in Journal of Economic Inequality, vol. 5, pp. 216-234, with an Introduction (pp. 213-215) by Peter Lambert.

Kolm, S.-C. (2004). Macrojustice: The Political Economy Of Fairness. Cambridge: University Press.

Lambert, P.J. (2004a). Income taxation and equity. Baltic Journal of Economics, vol. 4, no. 4, pp. 39-54.

Lambert, P.J. (2004b). Equivalence scales, horizontal equity and horizontal inequity. Pages 75-84 in C. Dagum and G. Ferrari (eds.) Household behaviour, equivalence scales, welfare and poverty. Heidelberg: Physica-Verlag. 
Lambert, P.J., D.L. Millimet and D. Slottje (2003). Inequality aversion and the natural rate of subjective inequality. Journal of Public Economics, vol. 87, pp. 1061-1090.

Lambert, P.J. and H.T. Naughton (2006). The equal sacrifice principle revisited. Economics Discussion Paper No. 2006-4, University of Oregon, and Working Paper No. 2006-45, Society for the Study of Economic Inequality (ECINEQ), Milan.

Quiggin, J. (1993). Generalized Expected Utility Theory: The Rank-Dependent Model. Dordrecht: Kluwer Academic Publishers.

Rawls, J. (1993). The Law of Peoples. Critical Inquiry, vol. 20, pp. 36-68.

Roemer, J.E. (1998). Equality of Opportunity. Harvard University Press, MA.

Roemer, J.E. (2006). Review essay: "The 2006 world development report: equity and development”. Journal of Economic Inequality, vol. 4, pp. 233-244.

Runciman, W.G. (1966). Relative Deprivation and Social Justice. London: Routledge.

Tsakloglou, P. and I. Cholezas (2005). Wage inequality in Europe: structure and intertemporal change" Report of the final EDWIN Workshop, Brussels, September $22^{\text {nd }}$.

World Development Indicators (2006). Washington D.C.: World Bank (and on the web).

Yaari, M. (1988). A controversial proposal concerning inequality measurement. Journal of Economic Theory, vol. 44, pp. 381-397.

Young, H.P. (1990). Progressive taxation and equal sacrifice. American Economic Review, vol. 80, pp. 253-266. 